Markus Köhler, Patrick Oßwald, Hongbin Xu, Trupti Kathrotia, Christian Hasse, Uwe Riedel, Speciation data for fuel-rich methane oxy-combustion and reforming under prototypical partial oxidation conditions, Chemical Engineering Science, Volume 139, (2016),249-260 .

The original publication is available at www.elsevier.com

[http://dx.doi.org/10.1016/j.ces.2015.09.033] 


\section{Speciation data for fuel-rich methane oxy-combustion and reforming under prototypical partial oxidation conditions}

Markus Köhler ${ }^{1}$, Patrick Oßwald ${ }^{1}$, Hongbin $X^{2}{ }^{2}$, Trupti Kathrotia ${ }^{1}$, Christian Hasse ${ }^{2}$, Uwe Riedel $^{1}$

1) Institute of Combustion Technology, German Aerospace Center (DLR), Pfaffenwaldring 38-40, D-70569 Stuttgart, Germany

2) Chair of Numerical Thermo-Fluid Dynamics, ZIK Virtuhcon, Technische Universität Bergakademie Freiberg, D-09599 Freiberg, Germany

Corresponding author: Markus Köhler

German Aerospace Center (DLR)

Pfaffenwaldring 38-40

D-70569 Stuttgart

Germany

Tel: +49 7116862756

Email: m.koehler@dlr.de 


\begin{abstract}
Non-catalytic partial oxidation (POX) of hydrocarbon fuels is an important process for producing syngas. Quantitative experimental data under the demanding conditions relevant for POX reactions, e.g. long residence times, rich stoichiometries and high temperatures, respectively, are rare in literature. Here, the DLR high-temperature flow reactor setup was used to obtain a unique experimental data set for validation of reaction models and general understanding of fuel-rich hydrocarbon chemistry. A systematic experimental speciation data set for rich methane conditions with relevance to partial oxidation / gasification processes is presented. Both fast oxidation and slow reforming reactions are considered here. Quantitative data is obtained in the DLR high temperature flow reactor setup with coupled molecular beam mass spectrometry (MBMS) detection. Five test case scenarios are investigated, featuring rich methane conditions ( $\phi=2.5$ ) for the temperature range from 1100-1800 K under atmospheric conditions. $\mathrm{CO}, \mathrm{CO}_{2}$ and acetylene in two different amounts is added to the system for systematic analysis for addressing phenomena related to partial oxidation. The new experimental database includes quantitative species profiles of major and intermediate species and is available as supplemental material. The experimental data is compared with results from a OD modeling approach using the GRI 3.0, USC-II, Chernov and a reduced model based on the full Chernov mechanism. The comparisons reveal significant differences in the model predictions among themselves and with respect to the experimental data, underlining the relevance of this unique data set for further mechanism development and/or optimization.
\end{abstract}

\title{
Keywords
}

1. Gasification

2. Rich combustion

3. Partial oxidation

4. Chemical modeling

5. Molecular-beam mass spectrometry (MBMS)

6. Flow reactor 


\section{Introduction}

Non-catalytic partial oxidation (POX) of hydrocarbon fuels is an important process for producing syngas - an indispensable intermediate product of numerous bulk chemicals such as methanol, ammonia or dimethyl ether and other synthetic fuels. The process is characterized by chemical reactions under fuel-rich or partial oxidation conditions and thus significantly different to stoichiometric and lean air-combustion. Although the overall process is characterized by fuel-rich / partial oxidation conditions, locally both stoichiometric reactions zones as well as under lean reforming zones can be found. For example, close to the burner, the fuel is oxidized - often using pure $\mathrm{O}_{2}$ as oxidizer leading to maximum flame temperatures around $3000 \mathrm{~K}$ - consuming most of the available oxidizer. The hot combustion products then mix with the remaining fuel in the reforming zone, which is characterized by much longer time scales compared to the combustion zone [1, 2]. In fact, non-catalytic partial oxidation processes can be considered similar to fuel-rich combustion, e.g. in premixed flames [1, 3], having a well-defined fast reaction zone and slow reforming reactions in the post-flame zone. In this study, we especially investigate the slow kinetics in the post-flame / reforming zone.

For design, optimization and control of POX reactors, experimental and numerical investigations are widely used in both research and applications. Zero-dimensional simulations of batch reactors [4-7] and one-dimensional simulations of premixed flames [8$11]$ or plug flow reactors $[12,13]$ are used to analyze the thermochemical process and validate the reaction mechanisms with experimental data.

Complementary experimental studies for partial oxidation/rich combustion investigate primarily processes with methane as fuel by using shock tubes [14-17], flow reactors [5, 7, 12, 18, 19], premixed flames [8-10, 20-25], partially premixed flames [26] and inverse diffusion flames [27-30]. A summary of the experimental investigations in simple chemical reactors for partial oxidation of methane can be found in [31]. Only a very limited number of studies looked at higher hydrocarbons including propene for partial oxidation conditions [32-35] and recently for reforming conditions with equivalence ratios up to 22 [36].

For numerical simulations, detailed chemical mechanisms are required. GRI-MECH 3.0 [37] or more generally GRI-MECH-based kinetic models are often used [8]. Furthermore, the Petersen mechanism [17], the mechanism from the University of Leeds [38], the Konnov mechanism [18], the Glarborg mechanism [13], the USC-II mechanism [39] and the mechanism from NUI Galway [40], respectively, were commonly employed. A comparison of 
some of these mechanisms can be found in [6] and [41]. Looking specifically at the results of Vascellari et al. [42] and of Guo et al. [43], it can be concluded that under POX conditions the concentration of $\mathrm{CO}$ can be overestimated, while the $\mathrm{CO}_{2}$ concentration is underestimated at the outlet of the reactors using the above-mentioned mechanisms. Further, the experimental data from Liu et al. [44] and $\mathrm{Li}$ et al. [31] show that the $\mathrm{C}_{2} \mathrm{H}_{2}$ concentration could not be reproduced accurately indicating another shortcoming of the mechanisms. To investigate the reactions under POX conditions systematically, especially for the influence of the intermediate species, detailed measurements are very much needed to analyze and potentially improve the mechanisms.

Quantitative experimental data to realize the demanding conditions relevant for POX reactions, e.g. long residence times, rich stoichiometries, and high temperatures are rare in literature. Here, the recently reported DLR high-temperature flow reactor setup [45] was used to obtain experimental data sets for validation purposes and a general understanding. Therefore, detailed speciation data was obtained from molecular beam sampling mass spectrometry at the reactor exhaust. This technique allows for simultaneous detection of almost all species involved including highly reactive species and has recently been applied successfully for the fundamental investigation of chemical reaction networks $[46,47]$ of e.g. novel biofuels such as alcohols [48], esters [49], or heterocyclic fuels [50-53].

Here this powerful technique monoatmospheric conditions and doped with $\mathrm{CO}, \mathrm{CO}_{2}$ and $\mathrm{C}_{2} \mathrm{H}_{2}$ to address the aforementioned points raised above systematically. As an initial approach towards understanding phenomena related to POX conditions, selected mechanisms with relevance to gasification are compared to the experimental data and discussed.

\section{Experimental method}

\subsection{Flow reactor experiment}

The DLR high-temperature flow reactor has been described elsewhere recently [45], so only a brief description is given here. A schematic of the reactor setup is shown in Fig. 1. The system consists of the high temperature reactor, including the gas supplies and the coupled gas analyzer i.e. a molecular beam mass spectrometry (MBMS) system. Gases are sampled directly at the reactor outlet and are transferred to the vacuum system of the time-of-flight mass spectrometer.

The reactor consists of an alumina $\left(\mathrm{Al}_{2} \mathrm{O}_{3}\right)$ ceramic tube with $40 \mathrm{~mm}$ inner diameter and a total length of $1497 \mathrm{~mm}$. The premixed gases are fed into the reactor by a tempered flange 
equipped with a porous bronze plug to create homogeneous flow conditions. The reaction segment has a total length of $1000 \mathrm{~mm}$, heated by a customized high temperature oven (Gero, Typ HTRH 40-1000). The setup is capable to provide temperatures up to $1900 \mathrm{~K}$ and heating/cooling rates up to $500 \mathrm{~K} / \mathrm{h}$ are applicable. Measurement series are performed at constant inlet flow conditions and a monotonically decreasing (-200 K/h) oven temperature ramp is applied. Thus, the residence time is dependent on the respective oven temperature. Careful characterization of the experimental setup with special focus on temperature measurements is described elsewhere [45]. The validity of the present approach is discussed and very good agreement of experimental results with accepted chemical kinetic models is found. Additionally, the same approach was also used successfully in other reactor experiments $[54,55]$. Conclusively, due to the excellent temperature reproducibility a relative precision of the measured temperatures of $\pm 5 \mathrm{~K}$ or better can be stated for the present reactor experiment.

Based on the discussion above with respect to optimization potentials of the chemical mechanisms, five test case studies were chosen for this investigation, as listed in Table 1 alongside the flow conditions. All cases feature fuel-rich partial oxidation conditions with an equivalence ratio of 2.5, relevant to previous studies on fuel-rich partial oxidation [27]. Starting from a $\mathrm{CH}_{4}$ base case (I), the second (II) and the third (III) case add $\mathrm{CO}_{2}$ and $\mathrm{CO}_{2} / \mathrm{CO}$ (1:1), respectively. These cases represent typical mixing of partially reacted products e.g. by recirculation, into the reaction zone. Cases IV and V specifically look at $\mathrm{C}_{2} \mathrm{H}_{2}$ addition since previous results mentioned above showed deficiencies in acetylene predictions. This is especially noteworthy since on one hand, $\mathrm{C}_{2} \mathrm{H}_{2}$ is an important soot precursor, where on the other hand $\mathrm{C}_{2} \mathrm{H}_{2}$ is produced as a chemical product under similar partial oxidation operating conditions [56]. Finally, given the high formation of $\mathrm{C}_{2} \mathrm{H}_{2}$, errors in the predictions might influence the temperature significantly.

Flow conditions themselves were designed to realize residence times around $2 \mathrm{~s}$ to match conditions relevant to the reforming zone in gasification processes. It is important to note that even for such long residence times, chemical equilibrium is not yet reached at the sampling nozzle. Values for CO are included in Fig. 2. This finding confirms that the reforming zone is dominated by slow reaction rates. Boundary conditions for lower residence times are limited by back diffusion of ambient air to the probing section; conditions were chosen to minimize or avoid these effects. The basis condition for the systematic study is a highly diluted ( 99.5 
mol\% Ar) premixed methane / oxygen gas mixture with an equivalence ratio of 2.5. High dilution is elementary for suppressing a self-sustaining combustion process, while the present conditions are the result of an optimization to minimize severe blocking of the nozzle by soot building and increase signal intensity.

The gas flows are regulated by calibrated mass flow controllers (Bronkhorst, Sevenstar, Tylan, range 0.1-15 slm $\mathrm{N}_{2}$ ), while fine dosage of methane was achieved by a Cori-Flow Coriolis mass flow meter (Bronkhorst, Mini Cori-Flow M12) optimized for low flow rates allowing for precise, well characterized inlet conditions. The total flow rate is on the order of 10 slm throughout the test case scenarios.

Table 1: Rich conditions for the oxidation of methane.

\begin{tabular}{|l|c|c|c|c|c|}
\hline Test case & I & II & III & IV & V \\
\hline Details & $\mathrm{CH}_{4}$-Basis & $+\mathrm{CO}_{2}$ & $+\mathrm{CO},+\mathrm{CO}_{2}$ & $+\mathrm{C}_{2} \mathrm{H}_{2}$ high & $+\mathrm{C}_{2} \mathrm{H}_{2}$ low \\
\hline Equivalence ratio & 2.5 & 2.5 & 2.5 & 2.5 & 2.5 \\
\hline $\mathrm{C} / \mathrm{O}$ & 0.625 & 0.556 & 0.571 & 0.667 & 0.634 \\
\hline $\mathbf{A r}$ & 9950 & 9950 & 9950 & 9950 & 9950 \\
\hline $\mathbf{C H}_{4}$ & 25 & 25 & 25 & 20 & 25 \\
\hline $\mathbf{O}_{2}$ & 20 & 20 & 25 & 18 & 20.5 \\
\hline $\mathbf{C O}$ & 0 & 0 & 25 & 0 & 0 \\
\hline $\mathbf{C O} \mathbf{O}_{2}$ & 0 & 25 & 50 & 0 & 0 \\
\hline $\mathbf{C}_{2} \mathbf{H}_{2}$ & 0 & 0 & 0 & 2 & 0.5 \\
\hline
\end{tabular}

Species detection was performed by time-of-flight (ToF) molecular beam mass spectrometer in a differential two-stage pumping scheme. The probing was achieved by placing the tip of sampling cone of the MBMS at position $\mathrm{x}=1471 \mathrm{~mm}$ downstream at the reactor centerline. Gases are withdrawn by a handmade quartz cone (QSIL Ilmenau) with an inner angle of $25^{\circ}$, $1.2 \mathrm{~mm}$ wall thickness and ca. $50 \mu \mathrm{m}$ opening to realize probing from atmospheric pressure. The molecular beam is skimmed $34 \mathrm{~mm}$ downstream of the nozzle tip with a Ni-skimmer (Beam Dynamics, model 76.2, $2 \mathrm{~mm}$ orifice) forming the molecular beam and directing the beam to the ion source of the spectrometer. Pressures for the present set of measurements are in the order of $5 \times 10^{-5}$ mbar in the first pumping stage and $5 \times 10^{-6}$ mbar in the ionization chamber respectively. This allows for sufficient quenching of any chemical reaction, while conserving the composition of the gas sample [47, 57]. 
Electron-Ionization (EI) near the ionization threshold of most organic compounds $(16 \mathrm{eV})$ is used to minimize fragmentation during the ionization process. Using a reflectron time-offlight spectrometer (Kaesdorf), a mass resolution $(\mathrm{m} / \Delta \mathrm{m})$ of 3000 is provided. This is sufficient to determine the elemental composition from the exact mass of the detected species when only $\mathrm{C}, \mathrm{H}$ and $\mathrm{O}$ atoms are considered.

\subsection{Data evaluation and uncertainties}

Quantitative data evaluation follows the well-established procedures of measurements in flames described in [58-61] and for reactor measurements [54, 62], so only a brief description is given here. For the present measurements, the integrated ion signal $S$ of a specific species $i$ is linked to its mole fraction $x$ by comparison with a respective signal of a reference species $R$. The electron-energy-dependent calibration factor $k_{i / R}(E)$ for the individual species is constituted from experimental constants:

$$
\frac{S_{i}}{S_{R}}=\frac{x_{i}}{x_{R}} \cdot k_{i / R}(E)
$$

From the given equation, the mole fractions are calculated with argon as the reference species. Its mole fraction can be considered constant due to the high dilution of the reactant gases $\left(x_{\mathrm{Ar}}\right.$ $=99.5 \%)$. Calibration factors are obtained by three strategies depending on the respective species: direct, internal and RICS method. Stable and commercially available species are calibrated directly by cold gas measurements, while major species (product and reactant species) are calibrated by an internal calibration procedure from the individual test case. Reactant species are calibrated using the signals at low temperatures, when the system is nonreactive and the composition corresponds to the inlet conditions. Product species are calibrated using the signals at high temperatures, where the composition can be obtained from the element balance and the experimental determination of the $\mathrm{CO} / \mathrm{CO}_{2}$ ratio. This important ratio was determined based on a commercial calibration gas reference, measured daily for each test case. Details on those procedures can be found in [54, 61]

Intermediate species are calibrated using binary gas mixtures, either commercially available or mixed via appropriate mass flow controllers. Whenever feasible the calibration factors versus argon are measured directly, once, for the complete series at unchanged experimental settings. For the remaining intermediate species, an estimation procedure was used. The RICS method (relative ionization cross section) [57] based on the measurement of electron ionization efficiency curves of chemically similar reference species is used for evaluation. An elaborate description is found in [58, 59, 61, 62]. A full overview on the applied calibration 
method for each species is listed in Tab. 2 alongside the determined maximum experimental mole fraction.

Statistical and relative uncertainties of single species typical for MBMS experiments in reactive environments are below $10 \%$ (standard deviation for poor signal-to-noise ratios is around $10 \%)$. Thus, a relative comparison of each species from different measurement runs offers a high precision. However, comparison with model predictions requires absolute uncertainties that are strongly dominated by the calibration method of choice and the consideration of fragmentation processes. Based on the current state of knowledge from similar MBMS experiments [55, 58-60], comparisons to kinetic models and own experiences, the uncertainty in the internal calibration is considered to be of the order of $15 \%$, while direct calibration is expected to have up to $20 \%$ uncertainty. For non-direct calibrated intermediates species, the uncertainty can be much higher on the order of 2-4. Those values are typically associated with the RICS method; details can be found in [61, 62].

\section{Kinetic modeling}

Although the focus of the contribution is on the new validation data sets, 0-D kinetic modeling based on a plug flow reactor model is presented to evaluate the suitability of wellestablished chemical mechanisms to model partial oxidation processes. The initial approach of chemical kinetic modeling is described in [45], therefor only a short description is given here. As a first approximation, a plug flow approach can be assumed; i.e. diffusion, axial as well as radial, is neglected and uniform velocity is assumed allowing for direct transformation of the spatial positon $\mathrm{x}$ to a distinct reaction (residence) time $\tau$. Consequently, a simple 0D consideration of the chemical kinetics (species and temperature evolution) as function of reaction time only is possible allowing for a systematic comparison of kinetic models with the obtained experimental data. Kinetic modeling was performed by using a 0D flow reactor approach based on the plug flow model of Chemical Workbench (CWB) [63]. The software offers the possibility to perform individual calculations for a high number of input temperature profiles. This enables the representation of the experimental temperature ramp with individual profiles for each oven temperature.

Standard input parameters to the flow reactor simulation are gas composition, pressure, reactor length, cross section and known mass flow rate as well as the axial temperature profile. Calculations are performed for 240 distinct temperature profiles and the resulting composition at the probe position is compared to the experimental value. The temperature 
profiles are derived and correlated to the respective oven temperature from a scaling procedure described in [45] based on experimentally determined centerline temperature profiles. There, the measured input temperature data is found as well.

Four mechanisms were chosen for kinetic simulations and comparisons with the experimental data. To the authors' knowledge, there is no detailed chemical kinetic mechanism available that is specifically adjusted to partial oxidation/fuel-rich conditions as investigated here. Thus, while the choice of mechanism above is definitely subjective to a certain degree, we feel that the results shown below can serve as a starting for further mechanism evaluation and development using the experimental data presented in this work. Selected are two common mechanisms for the simulation of gasification processes, the GRI-MECH 3.0 [37] and the USC-II [39] mechanism, which were successfully tested before for leaner $\mathrm{CH}_{4}$ and $\mathrm{C}_{2} \mathrm{H}_{4}$ conditions [45]. Especially for the widely validated USC-II mechanism, excellent agreement was reported for typical combustion conditions using the same modeling approach.

In addition, the mechanism presented by Chernov et al. [64] has been selected due to the reasonable performance in modelling a pilot-scale high-pressure partial oxidation (HP-POX) reactor [42] due to its improved C1-C2 chemistry basis. Since the GRI-MECH only accounts for C2 chemistry, we also include results obtained with a reduced CFD-suitable version of the Chernov mechanism (Chernov_C2) by simply neglecting all species with C3 and higher in the comparison below. Note that no further adjustments have been made to compensate the lack of C3 and higher species.

\section{Results and discussion}

Experimental data for rich methane conditions under controlled conditions is found rarely in literature, as described above. To our knowledge, the presented speciation data here provides the first systematic case study for these harsh conditions with relevance to gasification processes, while likewise addressing phenomena related to POX conditions. First and foremost, the data set is mainly intended to provide an experimental database for model validation purposes, and therefore, the complete experimental data set is provided in the supplemental material to this contribution.

The results from the laminar flow reactor experiment are presented in the following, accompanied with kinetic modeling for an initial discussion on the eligibility of selected models for the given conditions. While the first part focuses on the description of the experimental data set, a detailed discussion on selected phenomena concludes the contribution 
in the remaining section. The latter discussion is divided into major and intermediate species with the description of peculiar effects observed in the rich hydrocarbon chemistry.

\subsection{Experimental data}

All five test case conditions described above were measured and evaluated. In each measurement run, 17 species could be identified and quantified. Table 2 shows a list of all detected species with the calibration method of choice and maximum mole fraction. The full speciation data on the experimental results is available for download as supplemental material in ASCII format. Additional information can be found in [51] and is available on request.

Table 2: Major and intermediate species measured with MBMS in the laminar flow reactor. M: nominal mass; calibration method: "RICS"' (of reference species in parenthesis), “'Direct”' (cold-gas calibration), "Internal” (element balance); $x_{\max }$ Exp. peak mole fraction.

\begin{tabular}{|c|c|c|c|c|c|c|c|c|}
\hline Species & $\mathbf{M}$ & Calibrated as & $\begin{array}{l}\text { Calibration } \\
\text { Method }\end{array}$ & $\begin{array}{c}\text { Case I } \\
\mathrm{x}_{\max } \text { Exp. }\end{array}$ & $\begin{array}{r}\text { Case II } \\
\mathrm{x}_{\max } \text { Exp. } \\
\end{array}$ & $\begin{array}{l}\text { Case III } \\
\mathrm{x}_{\max } \text { Exp. }\end{array}$ & $\begin{array}{l}\text { Case IV } \\
\mathrm{x}_{\max } \text { Exp. }\end{array}$ & $\begin{array}{c}\text { Case V } \\
\mathrm{x}_{\max } \text { Exp. }\end{array}$ \\
\hline $\mathrm{H}_{2}$ & 2 & Hydrogen & Direct & 3.97E-03 & $2.60 \mathrm{E}-03$ & $1.46 \mathrm{E}-03$ & 3.04E-03 & 2.95E-03 \\
\hline $\mathrm{CH}_{4}$ & 16 & Methane & Internal & $2.68 \mathrm{E}-03$ & $2.46 \mathrm{E}-03$ & $2.54 \mathrm{E}-03$ & $2.02 \mathrm{E}-03$ & $2.56 \mathrm{E}-03$ \\
\hline $\mathrm{C}_{2} \mathrm{H}_{2}$ & 26 & Acetylene & Direct & $2.61 \mathrm{E}-04$ & 2.37E-04 & $1.94 \mathrm{E}-04$ & 2.65E-04 & $2.41 \mathrm{E}-04$ \\
\hline $\mathrm{CO}$ & 28 & Carbon monoxide & Internal & 2.17E-03 & 3.69E-03 & 5.71E-03 & $2.21 \mathrm{E}-03$ & 2.55E-03 \\
\hline $\mathrm{C}_{2} \mathrm{H}_{4}$ & 28 & Ethene & Direct & $1.34 \mathrm{E}-04$ & 1.19E-04 & $1.44 \mathrm{E}-04$ & $1.11 \mathrm{E}-04$ & $1.25 \mathrm{E}-04$ \\
\hline $\mathrm{O}_{2}$ & 32 & Oxygen & Internal & $2.04 \mathrm{E}-03$ & 2.03E-03 & 2.53E-03 & $1.84 \mathrm{E}-03$ & $2.09 \mathrm{E}-03$ \\
\hline $\mathrm{CO}_{2}$ & 44 & Carbon dioxide & Internal & 3.76E-04 & $2.57 \mathrm{E}-03$ & $5.05 \mathrm{E}-03$ & 3.08E-04 & 3.55E-04 \\
\hline $\mathrm{C}_{4} \mathrm{H}_{4}$ & 52 & Vinylacetylene & Direct & 3.86E-07 & 4.76E-07 & 2.83E-07 & 7.63E-07 & 4.54E-07 \\
\hline $\mathrm{C}_{2} \mathrm{H}_{6}$ & 30 & Ethane & Direct & 3.64E-05 & $3.20 \mathrm{E}-05$ & 4.00E-05 & $2.94 \mathrm{E}-05$ & 3.51E-05 \\
\hline $\mathrm{C}_{3} \mathrm{H}_{6}$ & 42 & Propene & Direct & $1.89 \mathrm{E}-06$ & $1.38 \mathrm{E}-06$ & 2.27E-06 & $1.14 \mathrm{E}-06$ & $1.35 \mathrm{E}-06$ \\
\hline $\mathrm{C}_{4} \mathrm{H}_{6}$ & 54 & 1,3-Butadiene & Direct & 8.96E-07 & 7.12E-07 & $4.68 \mathrm{E}-07$ & $1.65 \mathrm{E}-06$ & 7.47E-07 \\
\hline $\mathrm{C}_{4} \mathrm{H}_{2}$ & 50 & Vinylacetylene & $\operatorname{RICS}\left(\mathrm{C}_{4} \mathrm{H}_{4}\right)$ & 1.03E-05 & $9.18 \mathrm{E}-06$ & $3.98 \mathrm{E}-06$ & $9.31 \mathrm{E}-06$ & 8.86E-06 \\
\hline $\mathrm{C}_{3} \mathrm{H}_{3}$ & 39 & Propene & $\operatorname{RICS}\left(\mathrm{C}_{3} \mathrm{H}_{6}\right)$ & 8.12E-07 & $6.80 \mathrm{E}-07$ & $4.51 \mathrm{E}-07$ & 1.33E-06 & $6.21 \mathrm{E}-07$ \\
\hline $\mathrm{C}_{6} \mathrm{H}_{6}$ & 68 & Benzene & RICS $\left(\mathrm{C}_{6} \mathrm{H}_{6}\right)$ & 2.46E-06 & 2.49E-06 & 7.44E-07 & 2.36E-06 & 2.43E-06 \\
\hline $\mathrm{CH}_{2} \mathrm{O}$ & 30 & Formaldehyde & RICS $\left(\mathrm{C}_{2} \mathrm{H}_{4}\right)$ & $1.54 \mathrm{E}-05$ & $1.07 \mathrm{E}-05$ & 1.15E-05 & 8.42E-06 & $1.05 \mathrm{E}-05$ \\
\hline $\mathrm{C}_{2} \mathrm{H}_{2} \mathrm{O}$ & 42 & Ethenone & $\operatorname{RICS}\left(\mathrm{C}_{2} \mathrm{H}_{4}\right)$ & $9.47 \mathrm{E}-06$ & $6.45 \mathrm{E}-06$ & 3.09E-06 & $6.64 \mathrm{E}-06$ & 5.93E-06 \\
\hline
\end{tabular}

\subsection{Major species profiles}

Major species mole fractions from the EI-MBMS experiment are reported in Fig. 2 for the five test cases and compared with the modeling results for the 4 selected models described above. For reasons of clarity, the reactants methane and $\mathrm{O}_{2}$ are shown on the left hand side, while the major products $\mathrm{CO}, \mathrm{CO}_{2}$ and $\mathrm{H}_{2}$ are shown on the right hand side. Note that experimental values for $\mathrm{H}_{2} \mathrm{O}$ could not be obtained for all test cases due to the low concentrations obtained from combustion in addition to a high water background signal. 
However, reasonable profiles can be measured in principle as can be seen from remeasurements for test case I and II that are shown on the left side of Fig. 2. Remaining species of these re-measurements agree within the error tolerance.

The experimental data follows the profile shapes usually expected for combustion processes. No reactions are detected below $1200 \mathrm{~K}$, followed by a rapid consumption of methane and oxygen and formation of first products in the temperature range of 1200-1400 K. This is in agreement with the expected results, since low-temperature chemistry, i.e. the region exhibiting negative temperature coefficient (NTC) dominated by peroxide radicals, is unknown for methane combustion [65]. The main reactions are mostly completed around $1400 \mathrm{~K}$. Here, almost no oxygen is left, but a non-negligible amount of methane is found. Further reactions are observed in regions of interest up to $1800 \mathrm{~K}$ with decreasing methane and increasing $\mathrm{CO}$ and $\mathrm{H}_{2}$ amounts. The temperatures considered are typical for the fuel-rich post flame zone in non-catalytic partial oxidation. A detailed discussion on individual intermediate species can be found in section 4.2.

For the remainder of the discussion, the following parameters are compared: ignition temperature based on rapid fuel depletion (inflection point of methane mole fraction profile), $\mathrm{CO} / \mathrm{CO}_{2}$ ratio at $1420 \mathrm{~K}$ (right after ignition) and at $1800 \mathrm{~K}$, and the absolute $\mathrm{H}_{2}$ mole fraction at $1800 \mathrm{~K}$. To guide the reader through this detailed data, Tab. 3 is provided.

Table 3: Comparison of extracted experimental and modeled data.

\begin{tabular}{lcccc}
\hline & Ignition temperature & \multicolumn{2}{c}{ Product ratio CO/CO } & Mole fraction \\
& $\mathbf{C H}_{\mathbf{4}}$ & at $\mathbf{1 4 2 0} \mathbf{K}$ & at $\mathbf{1 8 0 0} \mathbf{~ K}$ & $\mathbf{H}_{\mathbf{2}}$ at $\mathbf{1 8 0 0} \mathbf{~ K}$ \\
\hline Test case I & & & & \\
Experiment & $1353 \mathrm{~K}$ & 5.09 & 6.39 & $3.97 \mathrm{E}-03$ \\
GRI 3.0 & $1347 \mathrm{~K}$ & 6.68 & 7.61 & $3.55 \mathrm{E}-03$ \\
Chernov_C2 & $1294 \mathrm{~K}$ & 4.18 & 5.89 & $3.19 \mathrm{E}-03$ \\
USC-II & $1345 \mathrm{~K}$ & 8.28 & 8.12 & $3.57 \mathrm{E}-03$ \\
Chernov & $1294 \mathrm{~K}$ & 5.08 & 9.01 & $3.62 \mathrm{E}-03$ \\
\hline Test case II & & & & \\
Experiment & $1355 \mathrm{~K}$ & 0.94 & 2.63 & $2.60 \mathrm{E}-03$ \\
GRI 3.0 & $1354 \mathrm{~K}$ & 0.72 & 2.80 & $2.26 \mathrm{E}-03$ \\
Chernov_C2 & $1297 \mathrm{~K}$ & 0.71 & 2.46 & $3.19 \mathrm{E}-03$ \\
USC-II & $1354 \mathrm{~K}$ & 0.71 & 2.84 & $2.26 \mathrm{E}-03$ \\
Chernov & $1297 \mathrm{~K}$ & 0.66 & 2.82 & $2.25 \mathrm{E}-03$ \\
\hline Test case III & & & & \\
Experiment & $1315 \mathrm{~K}$ & 0.86 & 1.41 & $1.46 \mathrm{E}-03$ \\
GRI 3.0 & $1330 \mathrm{~K}$ & 0.90 & 1.47 & $1.84 \mathrm{E}-03$
\end{tabular}




\begin{tabular}{lcccc} 
Chernov_C2 & $1253 \mathrm{~K}$ & 0.88 & 1.35 & $1.86 \mathrm{E}-03$ \\
USC-II & $1325 \mathrm{~K}$ & 0.88 & 1.48 & $1.62 \mathrm{E}-03$ \\
Chernov & $1253 \mathrm{~K}$ & 0.86 & 1.42 & $1.76 \mathrm{E}-03$ \\
\hline Test case IV & & & & \\
Experiment & $1319 \mathrm{~K}$ & 4.79 & 11.23 & $3.04 \mathrm{E}-03$ \\
GRI 3.0 & $1330 \mathrm{~K}$ & 6.49 & 7.80 & $3.02 \mathrm{E}-03$ \\
Chernov_C2 & $1255 \mathrm{~K}$ & 3.57 & 5.83 & $2.69 \mathrm{E}-03$ \\
USC-II & $1325 \mathrm{~K}$ & 8.04 & 8.50 & $3.05 \mathrm{E}-03$ \\
Chernov & $1255 \mathrm{~K}$ & 4.59 & 8.54 & $2.93 \mathrm{E}-03$ \\
\hline Test case V & & & & \\
Experiment & $1326 \mathrm{~K}$ & 5.71 & 10.53 & $2.95 \mathrm{E}-03$ \\
GRI 3.0 & $1344 \mathrm{~K}$ & 6.45 & 7.30 & $3.55 \mathrm{E}-03$ \\
Chernov_C2 & $1287 \mathrm{~K}$ & 3.81 & 5.66 & $3.22 \mathrm{E}-03$ \\
USC-II & $1327 \mathrm{~K}$ & 7.80 & 7.76 & $3.56 \mathrm{E}-03$ \\
Chernov & $1284 \mathrm{~K}$ & 4.82 & 8.51 & $3.60 \mathrm{E}-03$ \\
\hline
\end{tabular}

\subsubsection{Ignition temperature comparison}

Comparing the ignition temperatures between the test cases themselves and between the experimental and modeled data, noteworthy effects are observed. First, the ignition temperature of $1353 \mathrm{~K}$ for case I and $1355 \mathrm{~K}$ for case II are similar, while adding CO to the system in test case III increases the reactivity and shifts the ignition temperature to a lower value of $1315 \mathrm{~K}$. The same shift to a lower ignition temperature can be observed with the addition of acetylene in case IV and V as well. The comparison of the experimental ignition temperature with the modeled results shows a very good agreement for the GRI 3.0 and USCII mechanisms and results are well within the expected error limits. The model prediction shows the same trends in temperature shift as the experimental results.

With respect to the major species and global parameters such as ignition temperature, the reduced Chernov_C2 model behaves very similar to the detailed base Chernov mechanism. However, both mechanisms predict the ignition temperature in the range of 60-70 K lower compared to the other models and the experimental data. The shift of the Chernov mechanisms to lower temperatures is in agreement with the formation of the products, also forming 60-70 K earlier. This is observed for the five test cases: Good agreement of the GRI 3.0 and USC-II, striking lower prediction of the ignition temperature by the Chernov mechanisms and good trend prediction (i.e. profile shapes). For comparison, the ignition delay times are calculated for similar conditions (see supplement). Similar behavior is found i.e. faster ignition (shorter delay times) for the Chernov mechanisms compared to the GRI 3.0 and USC-II, and is able to explain the shift described above. A detailed investigation on the 
relevant reactions involved does not reveal a conclusive picture, however, the reaction rate of $\mathrm{CH}_{3}+\mathrm{O}_{2} \rightarrow \mathrm{CH}_{2} \mathrm{O}+\mathrm{OH}$ is identified in the Chernov mechanisms for the discrepancy to the USC-II and GRI 3.0. A change of the reaction rate easily shifts the ignition delay by a factor of 2 for the given temperature regime (see supplement). The calculated ignition delay times are provided in the supplemental material alongside a comparison of the rate constants of the reaction above. Conclusively, the GRI 3.0 and USC-II appear suitable for predicting the ignition temperature of the investigated rich methane systems.

\subsection{2 $\mathrm{CO} / \mathrm{CO}_{2}$ ratio comparison}

The comparison of the $\mathrm{CO} / \mathrm{CO}_{2}$ mole fraction ratios shows a rather complex picture for the rich methane conditions investigated here. In general, mole fraction ratios are selected for $1420 \mathrm{~K}$ and $1800 \mathrm{~K}$ from the experimental results and the predicted model data are listed in Tab. 3. The temperatures were chosen for investigating phenomena, attributed to two different regions: First, the ignition process and its related reactions right after ignition that are found in the $1420 \mathrm{~K}$ temperature regime. These reactions appear to be similar to the conventional combustion reactions and are relatively well understood.

The further evolution of the $\mathrm{CO} / \mathrm{CO}_{2}$ ratio in the post ignition regime (here up to $1800 \mathrm{~K}$ ) is the focus here. For closer investigation, two temperatures in the post ignition regime are selected. The experimental data shows an increase in the $\mathrm{CO} / \mathrm{CO}_{2}$ mole fraction ratio from $1420 \mathrm{~K}$ to $1800 \mathrm{~K}$ of roughly a factor of 2-2.5. The exception is observed in test case I, where the ratio at $1800 \mathrm{~K}$ with 6.39 is only slightly higher compared to $1420 \mathrm{~K}$ with 5.09. Regarding the results from the four models, the experimental trend of an increased mole fraction ratio for $1800 \mathrm{~K}$ is not observed throughout and some predicted results appear arbitrary at first glance. Focusing on test case II and III first, the comparison shows similar results for the modeled data. In addition, a good agreement between the models and the experimental data can be reported for the test case II (addition of $\mathrm{CO}_{2}$ ) and test case III (addition of $\mathrm{CO}$ and $\mathrm{CO}_{2}$ ) with deviations below $10 \%$ being very well within the experimental uncertainty. However, noticeable discrepancies in the modeled predictions of the $\mathrm{CO} / \mathrm{CO}_{2}$ mole fraction ratios are observed for the remaining test cases I, IV and V. The model predictions differ among themselves for both temperature regimes, highlighting the demand of validation experiments for the present reaction conditions.

The addition of acetylene in test cases IV and V offer the most significant deviation between the model predictions for $1420 \mathrm{~K}$ and $1800 \mathrm{~K}$. Note that for $1800 \mathrm{~K}$, all $\mathrm{CO} / \mathrm{CO}_{2}$ ratio predictions with acetylene addition are noticeably lower than the experimental data. In test 
case $\mathrm{V}$ with less acetylene addition, the spreading of the modeled mole fraction ratio declines, but is still beyond the expected uncertainties. Looking at the sole mole fractions of CO in Fig. 2, distinct deviations are observed for the modeled data, too. The same observations made above are, to a lesser degree, applicable for test case I offering no new insights other than a random spreading of the modeled predictions. For $1420 \mathrm{~K}$, the Chernov mechanism offers a very good prediction to the experimental data, while for $1800 \mathrm{~K}$ the GRI 3.0 is closer to the experimental data, revealing no coherent picture.

As an initial source of discussion, an investigation of the main $\mathrm{CO} / \mathrm{CO}_{2}$ conversion reaction rate offers a first insight. Looking at the main reactions rates for $\mathrm{CO} / \mathrm{CO}_{2}$, especially the reaction $\mathrm{CO}+\mathrm{OH} \rightarrow \mathrm{CO}_{2}+\mathrm{H}$ for the given mechanisms is identified (data provided in the supplemental material). The deviation of the rates for this reaction is found to be below $10 \%$ for the temperature range of 300-2000 K. To influence the mole fractions to the degree observed here, a major influence of the intermediate chemistry seems very likely. Note that the investigated models are not validated comprehensively for these harsh conditions of higher stoichiometry presented here, so deviations from experimental results are not unexpected. A full analysis of the various random model behavior observed here is beyond the scope of this experimental contribution.

\subsection{3 $\mathrm{H}_{2}$ mole fraction comparison}

Finally, a comparison of the mole fraction results of $\mathrm{H}_{2}$ for $1800 \mathrm{~K}$ shows a good agreement with the model prediction for all text five cases. Deviations are very well within the $20 \%$ uncertainty level despite the bad $\mathrm{S} / \mathrm{N}$ ratio of $\mathrm{H}_{2}$ due to its low ionization cross section at this electron energy. The computed data is also in good agreement with the experimental results and features the same trends in concentration change for the test cases. Interestingly, while four test cases show comparable concentrations, the biggest change is obtained with the addition of CO in test case III. Here, the overall amount of carbon in the input conditions is the highest for all test cases, but an additional amount of oxygen is added to the system in order to match the target stoichiometry. Furthermore, conversion of $\mathrm{CO}_{2}$ towards $\mathrm{CO}$ releases an additional amount of oxygen (compare Fig. 2) resulting in a relatively leaner reaction environment as in the other test cases.

To summarize the first comparison for the rich methane conditions investigated here, the experimental ignition temperature around $1350 \mathrm{~K}$ is predicted quite well by the GRI 3.0 and USC-II, while the prediction of the global chemistry of major species is mixed at best. Methane, $\mathrm{O}_{2}$ and $\mathrm{H}_{2}$ are in reasonable to good agreement, while the $\mathrm{CO} / \mathrm{CO}_{2}$ mole fraction 
ratios reveal an incoherent picture, especially when additional acetylene is introduced into the system.

\subsection{Intermediate species profiles}

The focus of this contribution is the presentation of the newly measured data sets suitable for model validation. However, the new data set offers several noteworthy findings and observed effects - a selection of those is presented in the following discussion of intermediate species. Figure 3 shows the experimental and predicted mole fraction profiles of the $\mathrm{C}_{2} \mathrm{H}_{2}, \mathrm{C}_{2} \mathrm{H}_{4}$ and $\mathrm{C}_{2} \mathrm{H}_{6}$ intermediates for selected test cases I, III and IV. In order to keep an overview for the following discussion, these three test cases were selected for discussion to demonstrate the most extreme effects observed. In general, the omitted case II shows a close resemblance to the base test case I and test case V compares well in particular to test case IV, thus both are not mandatory for the detailed discussion on intermediates. See supplemental material for the complete dataset, including all five test cases.

Acetylene, as one of the important intermediate species in the soot formation pathways provides the basis for further discussion. The general shape of the experimental acetylene profile exhibits a rapid formation peak in the range of 1320-1350 K, which is followed by a plateau region. The consumption in test case I is also rather rapid at $1640 \mathrm{~K}$, while test case III shows a more steady consumption slope starting at $1550 \mathrm{~K}$ and test case IV shows an even slower decrease in concentration starting at $1550 \mathrm{~K}$ with a rapid depletion at $1710 \mathrm{~K}$. Mole fractions are all on the order of $2.7 \times 10^{-4}$. The general shape is somewhat peculiar, since most other intermediates follow the expected intermediate shape as seen in Fig. 3 for ethylene and ethane with a rapid formation near the ignition region followed by a sharp depletion before $1400 \mathrm{~K}$.

The model predictions of acetylene are rather discordant for all models probed in all test cases. Regarding the data for test case I, three striking effects can be observed: First, in agreement with the findings from the major species, the Chernov and reduced Chernov_C2 show ignition temperatures $60 \mathrm{~K}$ below the other predictions and the experimental data i.e. profile onsets for $\mathrm{C}_{2} \mathrm{H}_{2}$ and peak temperatures of intermediates such as $\mathrm{C}_{2} \mathrm{H}_{4}$ and $\mathrm{C}_{2} \mathrm{H}_{6}$ are shifted accordingly. The GRI 3.0 and USC-II predict the ignition temperature with $1350 \mathrm{~K}$ very well. Second, the maximum acetylene mole fraction predictions are consistently higher than the direct calibrated measurements. Moreover, the model predictions cover a range in mole fraction of $3.2-5.8 \times 10^{-4}$ and differ by a factor of 2 . In comparison with the experimental data, the plateau shape of the profile is covered to a certain degree by the model predictions. 
However, the profile shapes also differ significantly between the models themselves. Third, this discordant trend is also observed for the depletion of acetylene in the high temperature regime. Predictions at $1700 \mathrm{~K}$ for example vary by a factor of 3-4 and the overall acetylene consumption is not in agreement with the experimental data for test case I. The observed sharp drop in concentration described above in the experimental results is not predicted by any mechanism.

With the addition of $\mathrm{CO}_{2}$ and $\mathrm{CO}$ in test case III, the overall picture of the predictions changes dramatically. While no change in the ignition temperature is observed in comparison to test case I, maximum mole fractions are lower when compared to test case I. This finding may be attributed to the additional amount of oxygen added to match the target stoichiometry as mentioned before. The prediction of GRI 3.0 is in excellent agreement with profile shape and concentration of the experimental data, closely followed by the USC-II, where still a good agreement can be reported. Only the acetylene consumption shows a minor deviation in both predictions. The Chernov mechanism still over-predicts the peak mole fraction by a factor of 2, while the acetylene consumption is in very good agreement for higher temperatures (1600 K and above) with USC-II, GRI 3.0 and Chernov_C2 over-predicting the acetylene concentration in this region.

Test case IV adds $\mathrm{C}_{2} \mathrm{H}_{2}$ to the system and model predictions show significant difference among each other. The Chernov mechanism, again, shows excellent agreement in the acetylene consumption region, but maximum mole fractions are over-predicted. GRI 3.0 and USC-II predict the plateau regime best, but are both still slightly higher than the experimental finding. The initial acetylene consumption below the ignition temperature is only covered properly by the Chernov mechanism. In omitting a large part of relevant C3 chemistry linking to acetylene, the Chernov_C2 shows a significant over-prediction throughout as can be expected. However, the profile shape is still captured quite well.

An investigation on the rate of productions (ROP) of acetylene gives more insight. Test case I, II and IV were investigated for 8 temperatures ranging before, during and after ignition and some patterns were found in the formation and consumption channels.

- Formation: The major formation channel in all mechanisms in the temperature range of $1200-1400 \mathrm{~K}$ is $\mathrm{C}_{2} \mathrm{H}_{3}+\mathrm{M} \rightarrow \mathrm{C}_{2} \mathrm{H}_{2}+\mathrm{H}+\mathrm{M}$. This reaction is the final step in the consecutive dehydrogenation chain starting with ethane $\left(\mathrm{C}_{2} \mathrm{H}_{6}\right)$, originating from methyl recombination $[25,66,67]$ as commonly seen in flames. The GRI 3.0 shows no $\mathrm{C}_{2} \mathrm{H}_{2}$ formation above $1360 \mathrm{~K}$, while the C3-C4 hydrocarbon chemistry of the 
USC-II and Chernov mechanisms contribute significantly to the $\mathrm{C}_{2} \mathrm{H}_{2}$ formation above $1420 \mathrm{~K}$.

- Consumption: No coherent picture can be found here and consumption varies significantly in the mechanisms investigated. However, the USC-II and GRI 3.0 indicate major consumption by $\mathrm{HCCO}$ and/or $\mathrm{CH}_{2} \mathrm{CO}$ channels. The Chernov mechanism shows a rather complex picture, with typical main consumption at lower temperatures below $1300 \mathrm{~K}$ to $\mathrm{C}_{3} \mathrm{H}_{5}$, in the range of $1300-1600 \mathrm{~K}$ to $\mathrm{C}_{5} \mathrm{H}_{5}$ and above $1600 \mathrm{~K}$ to $\mathrm{C}_{4} \mathrm{H}_{2}$.

The noticeable differences in the model predictions can be connected to the complex picture from the ROP analysis, showing no coherence with respect to the acetylene consumption.

Depending on the parameter of interest, either ignition temperature or acetylene formation/destruction is predicted well. Reasons for the incoherent picture of the models for acetylene may be connected to the lack of soot and/or soot precursor modeling in the chosen mechanisms, since the investigation of the rich methane conditions is accompanied by soot production even at high dilution. Thus, an over-prediction by the model seems possible since no carbon loss due to soot formation is present. Acetylene is furthermore present in high concentrations and closely linked to the soot formation processes so that high impact of losses due to soot formation appears likely. The very same argument of the lack of soot precursor/ soot chemistry should be valid for the discussion with respect to benzene as well. This will be shown in the latter part, when results for benzene are discussed.

The remaining six plots in Fig. 3 show the experimental and simulated profiles of $\mathrm{C}_{2} \mathrm{H}_{4}$ and $\mathrm{C}_{2} \mathrm{H}_{6}$. In general, a good predictive capability, in terms of profile shape and mole fraction can be reported for test case I and III. Note that the Chernov and Chernov_C2 mechanisms feature a lower ignition temperature and mole fractions as discussed above. Both yield identical results for all cases, which indicate the insignificance of larger hydrocarbons in the initial fuel decay reactions. With addition of acetylene in test case IV, the models reveal their different treatment of the acetylene destruction. While all predictions are still within a factor of 2, it is striking to see the sensitive effect of additional $2 \mathrm{sccm}$ acetylene to the reacting system. The profile shape for $\mathrm{C}_{2} \mathrm{H}_{4}$ and $\mathrm{C}_{2} \mathrm{H}_{6}$ is narrow and sharp for the first two test cases, while the overall shape gets broader and the maximum position shifts to lower temperatures by $40 \mathrm{~K}$ for the experimental data as well as for all model predictions except the GRI 3.0

Note that more intermediate species are featured in the supplemental material. The observed trends and effects are underlined leading to a general statement: While the models show a 
good prediction of intermediate species (e.g. ethane), the test cases with addition acetylene show the most severe deviations. Since acetylene is present in significant concentrations even at high-temperature conditions and is closely linked to soot percurser and soot chemistry, the next logical step is the comparison of benzene as another improtant soot precursor. Figure 4 shows the experimental and predicted benzene mole fraction profiles for the selected test cases. Note that the GRI 3.0 along with the reduced Chernov_C2 model does not include $\mathrm{C}_{6} \mathrm{H}_{6}$, so the discussion is focussed on the USC-II and the Chernov predictions.

The rich methane conditions in test case I show an intermediate profile for the experimental benzene data with a maximum at $1470 \mathrm{~K}$ and $2.4 \mathrm{ppm}$. The USC-II mechanism over-predicts the experimental result by a factor of 6 with a shift of the maximum to a slightly higher temperature of $1490 \mathrm{~K}$. The Chernov model prediction on the other hand is in very good agreement in terms of mole fraction, profile shape and maximum position. Note that both model predictions vary by a factor of 6 amongst themselves. With the addition of CO in test case III, the deviations of the model predictions are smaller, but still in the order of factor 4 . The consumption of benzene is still predicted at higher temperatures. Again, the Chernov mechanism shows an overall very good agreement. The noticeable over-prediction by the USC-II may be attributed to the uncaptured carbon loss due to sooting - the elemental balance indicates that up to $10 \%$ of carbon could not be detected in the respective temperature regime. Test case IV shows new striking effects with the addition of additional acetylene. Foremost, the experimental data features a bimodal structure of the benzene mole fraction with two distinct maxima: the first maximum is at $1290 \mathrm{~K}$ and the second at a higher temperature of $1459 \mathrm{~K}$. The mole fractions themselves are compareable to the test cases before. The second maximum is in the same high temperature regime as in test case I and III; similar benzene formation channels can be assumed here for all conditions. The first benzene peak in the low temperature regime (test case IV) is clearly linked to the presence of acetylene as fuel.

The model predictions are basically comparable with test case I in position, shape and mole fraction. However, in contrast to the Chernov mechanism the USC-II mechnanism features the bimodal shape as well and predicts the maximum at a lower temperature of $1290 \mathrm{~K}$, which is quite well within the error of the temperature determination. A closer analysis of the USCII mechanism reveals a direct connection of the propargyl $\mathrm{C}_{3} \mathrm{H}_{3}$ recombination reaction to the first benzene maximum at $1290 \mathrm{~K}$. Propargyl recombination is also seen to be the dominat formation pathway in many flames [68]. A comparison of rate constants for the recombination reaction, presented in the supplemental material, indicates severe differences for the USC-II 
and the Chernov mechanism, but both mechanisms are comparable for the temperature regime around $1200-1300 \mathrm{~K}$. The second maximum is found to be linked to the propargyl species as ROP analysis showed. However, the benzene formation is not attributed to a simple recombination reaction, but rather a complex interaction of several pathways involving $\mathrm{C}_{6} \mathrm{H}_{5}$, $\mathrm{C}_{4} \mathrm{H}_{5}, \mathrm{C}_{4} \mathrm{H}_{3}$ and other C3-C6 species. These implications to the reaction chemistry of benzene may be the basis for an in-depth investigation of the formation of soot precursors in rich methane conditions.

Fig. 5 shows a comparison of the propargyl radical $\mathrm{C}_{3} \mathrm{H}_{3}$ mole fraction; note that $\mathrm{C}_{3} \mathrm{H}_{3}$ as a radical species is calibrated by the RICS method and thus absolute mole fractions must be considered with care. The experimental profiles show an intermediate profile shape for all test cases with maximum concentrations in the range of $4 \times 10^{-7}-1.3 \times 10^{-6}$. Test case 4 shows the highest mole fraction and additionally a distinct bimodal distribution: the first maximum is found at $1240 \mathrm{~K}$ and the second at $1420 \mathrm{~K}$. With regard to the discussion above on the bimodal benzene distribution, the strong link assumed earlier between benzene and propargyl seems very likely from the given experimental data here.

Model predictions indicate a rather complex picture. Starting with test case I, the USC-II and Chernov results of $\mathrm{C}_{3} \mathrm{H}_{3}$ under-predict the mole fraction by a factor of 2-4. Taking the experimental quarry for a radical species into account, agreement is reasonable to good. However, the experimental maximum is at $1420 \mathrm{~K}$, while peak concentrations for the Chernov prediction is at $1560 \mathrm{~K}$ and the USC-II shows a broad distribution up to $1800 \mathrm{~K}$ with no clear maximum. For both predictions their hypothesis shifted to significantly higher temperatures. Adding CO to the system (test case III) shows little change in the USC-II prediction. The prediction by Chernov, however, a better agreement can be reported for profile shape, maximum position at $1500 \mathrm{~K}$ and mole fraction. Moreover, the experimental data shows a sharp maximum peak at $1315 \mathrm{~K}$ that is partially recovered by the Chernov prediction as well. Finally, in test case IV with the addition of acetylene, the model predictions are comparable to the previous test cases with no significant change. Both mechanisms fail to predict the high mole fraction of the first experimental propargyl mole fraction peak profile at $1240 \mathrm{~K}$. The experimental data presented here suggests $\mathrm{C}_{3} \mathrm{H}_{3}$ reactions around the $1300 \mathrm{~K}$ and $1600 \mathrm{~K}$ regions that seem linked to the formation of benzene for these rich methane conditions. This assumption is backed up by a separate ROP analysis for both mechanisms indicating a complex C3 interaction with benzene. However, C4 species are likely found to be negligible 
for the given systems at present state. A proper prediction of the propargyl reactions conclusively fails at high temperatures $\left(\mathrm{C}_{3} \mathrm{H}_{3}\right.$ peaks later than $\left.\mathrm{C}_{6} \mathrm{H}_{6}\right)$ as well as at low temperatures for the USC-II and the Chernov mechanism.

Finally, we focus on the oxygenated species formaldehyde and ethenone with mole fraction profiles shown in Fig. 6. Starting with formaldehyde, the predictions from the USC-II and GRI 3.0 are compareable for the three selected test cases. Comparison with the experimental data shows a very good agreement for the first test case. Over-prediction of a factor of 3-4 is stated for the Chernov and Chernov_C2 models. Again, identical results are obtained for both mechanisms indicating the insignificance of C3 species on the formaldehyde profile. Some differences with the addition of acetylene in test case IV results are observed, however. This changes when the next oxygenated species ketene (ethenone) is compared. Test case I and III show a reasonable to good prediction of the maximum position for all models with the experimental data. The GRI 3.0 over-predicts slightly for the rich methane case I and by a factor of 6-7 for the addition of CO. The remaining models show reasonable agreement. Note that the measurements exhibit a small dip in the peaks, which is not reproduced by the models. Since the resulting bimodality of the profile is not as pronounced as for other species (e.g $\mathrm{C}_{3} \mathrm{H}_{3}$ ), small instabilities of the system cannot be excluded completely.

For test case IV, the addition of acetylene leads to significant deviations. The experimental mole fraction maximum at $1365 \mathrm{~K}$ is similar to the other test cases. However, a second maximum at a lower temperature of $1240 \mathrm{~K}$ occurs similarly to benzene and $\mathrm{C}_{3} \mathrm{H}_{3}$.

The Chernov mechanism shows an early maximum with an under-prediction of a factor of 2-3 and omits the second maximum. The same peak position is observed for the USC-II mechanism, however, over-prediction of 2-3 is observed. In contrast, the GRI 3.0 mechanism does not change the peak temperature with acetylene addition. The result, however, represents the second maximum of the experimental profile quite well. Moreover, this demonstrates the challenge and optimization potential of present models for these demanding conditions that are relevant for gasification processes.

\section{Summary and conclusions}

We present the first systematic experimental speciation data for rich methane conditions with relevance to partial oxidation / gasification processes. Both, fast oxidation and slow reforming reactions are considered here. Quantitative data is obtained by the DLR high temperature flow 
reactor setup with coupled MBMS detection. Five test case scenarios are investigated, featuring rich methane conditions $(\phi=2.5)$ for the temperature range from 1100-1800 K under atmospheric conditions. $\mathrm{CO}, \mathrm{CO}_{2}$, and acetylene in two different amounts is added to the system for systematic analysis for addressing phenomena related to partial oxidation. The new experimental database includes quantitative species profiles of major products and intermediate species. The experimental data is available as supplemental material for validation purposes.

In addition, a 0-D modeling approach is presented alongside the experimental results. Here, the GRI 3.0, USC-II, Chernov, and a reduced model based on the full Chernov mechanism are used for an initial discussion of the experimental data. In general, the experimental ignition temperature around $1350 \mathrm{~K}$ is predicted quite well by the GRI 3.0 and USC-II mechanisms. However, the prediction of the global chemistry shown for the major species is mixed at best. Fuel, $\mathrm{O}_{2}$ and $\mathrm{H}_{2}$ are in reasonable to good agreement, while the $\mathrm{CO} / \mathrm{CO}_{2}$ mole fraction ratios reveal arbitrary results from the investigated models, especially when acetylene is added to the system. The obtained bimodal distributions in the benzene mole fractions are discussed alongside other relevant hydrocarbon intermediate profiles. The comparisons reveal significant differences in the model predictions among themselves, underlining the relevance of this unique data set for further mechanism optimizations.

Currently, the significant differences in the model predictions and with respect to the experimental data are very likely to be linked to the lack of soot precursor and/or soot chemistry. This aspect seems to play a vital role in rich methane combustion and is suggested to be considered for further mechanism development and/or optimization in this area.

\section{Acknowledgements}

The authors acknowledge the financial support by the Federal Ministry of Education and Research of Germany in the framework of Virtuhcon (project number 03Z2FN11). P.O. and M.K. thank the DLR Center-of-Excellence “Alternative Fuels“ for financial support. P. Kutne and P. Le Clercq are gratefully acknowledged for fruitful discussions. We thank L. Kracht and R. Whitside for their help with measurements and preparation of this manuscript. 


\section{References}

[1] J. Caudal, B. Fiorina, M. Massot, B. Labégorre, N. Darabiha, O. Gicquel, Proc. Combust. Inst., 34 (2013) 1357-1364.

[2] U. Prüfert, F. Hunger, C. Hasse, Combust. Flame, 161 (2014) 416-426.

[3] J. Caudal, B. Fiorina, B. Labégorre, O. Gicquel, Fuel Process. Technol., 134 (2015) 231-242.

[4] Z. Al-Hamamre, S. Voss, D. Trimis, Int. J. Hydrogen Energy, 34 (2009) 827-832.

[5] R.J. Berger, G.B. Marin, Ind. Eng. Chem. Res., 38 (1999) 2582-2592.

[6] S. Cao, D. Wang, T. Wang, Chem. Eng. Sci., 65 (2010) 2608-2618.

[7] B. Lemke, C. Roodhouse, N. Glumac, H. Krier, Int. J. Hydrogen Energy, 30 (2005) 893-902.

[8] C.H. Smith, D.I. Pineda, J.L. Ellzey, Combust. Flame, 160 (2013) 557-564.

[9] A. Turbiez, A. El Bakali, J.F. Pauwels, A. Rida, P. Meunier, Fuel, 83 (2004) 933-941.

[10] H. Watanabe, F. Arai, K. Okazaki, Combust. Flame, 160 (2013) 2375-2385.

[11] J. Zhu, D. Zhang, K.D. King, Fuel, 80 (2001) 899-905.

[12] S. Han, J. Park, S. Song, K.M. Chun, Int. J. Hydrogen Energy, 35 (2010) 8762-8771.

[13] M.S. Skjoth-Rasmussen, P. Glarborg, M. Ostberg, J.T. Johannessen, H. Livbjerg, A.D. Jensen, T.S. Christensen, Combust. Flame, 136 (2004) 91-128.

[14] Y. Levy, E. Olchanski, V. Sherbaum, V. Erenburg, A. Burcat, J. Propul. Power, 22 (2006) 669676.

[15] A. Lifshitz, K. Scheller, A. Burcat, G.B. Skinner, Combust. Flame, 16 (1971) 311-321.

[16] D.B. Olson, W.C. Gardiner Jr., Combust. Flame, 32 (1978) 151-161.

[17] E. Petersen, D. Davidson, R. Hanson, Combust. Flame, 117 (1999) 272-290.

[18] A. Konnov, J.N. Zhu, J.H. Bromly, D.K. Zhang, Combust. Sci. Technol., 176 (2004) 1093-1116.

[19] C.L. Rasmussen, Jakobsen, G. J. G., Int. J. Chem. Kinet., 40 (2008) 778-807.

[20] J.H. Bechtel, R.J. Blint, C.J. Dasch, D.A. Weinberger, Combust. Flame, 42 (1981) 197-213.

[21] M.J. Castaldi, A.M. Vincitore, S.M. Senkan, Combust. Sci. Technol., 107 (1995) 1-19.

[22] S.G. Davis, C.K. Law, Combust. Sci. Technol., 140 (1998) 427-449.

[23] F.N. Egolfopoulos, P. Cho, C.K. Law, Combust. Flame, 76 (1989) 375-391.

[24] C.J. Langley, A.R. Burgess, Proc. Roy. Soc. A, 421 (1989) 259-278.

[25] M. Musick, P.J. VanTiggelen, J. Vandooren, Combust. Flame, 105 (1996) 433-450.

[26] U. Struckmeier, A. Lucassen, N. Hansen, T. Wada, N. Peters, K. Kohse-Höinghaus, Combust. Flame, 157 (2010) 1966-1975.

[27] B. Stelzner, F. Hunger, A. Laugwitz, M. Grabner, S. Voss, K. Uebel, M. Schurz, R. Schimpke, S. Weise, S. Krzack, D. Trimis, C. Hasse, B. Meyer, Fuel Process. Technol., 110 (2013) 33-45.

[28] F. Hunger, B. Stelzner, D. Trimis, C. Hasse, Flow Turbul. Combust., 90 (2013) 833-857.

[29] B. Stelzner, F. Hunger, S. Voss, J. Keller, C. Hasse, D. Trimis, Proc. Combust. Inst., 34 (2013) 1045-1055.

[30] B. Garten, F. Hunger, D. Messig, B. Stelzner, D. Trimis, C. Hasse, Int. J. Therm. Sci., 87 (2015) 68-84.

[31] C.E. Li, N. Burke, K. Gerdes, J. Patel, Fuel, 109 (2013) 409-416.

[32] G.G. Alatorre, H. Böhm, B. Atakan, K. Kohse-Höinghaus, Z. Phys. Chem., 215 (2001) 981-995.

[33] B. Atakan, A. Lamprecht, K. Kohse-Höinghaus, Combust. Flame, 133 (2003) 431-440.

[34] K. Kohse-Höinghaus, M. Kamphus, G.G. Alatorre, B. Atakan, A. Schocker, A. Brockhinke, Comptes Rendus de l'Académie des Sciences - Series IV - Physics, 2 (2001) 973-982.

[35] A. Lamprecht, B. Atakan, K. Kohse-Höinghaus, Proc. Combust. Inst., 28 (2000) 1817-1824.

[36] F. Sen, T. Kasper, U. Bergmann, R. Hegner, B. Atakan, Z. Phys. Chem., 229 (2015) 955-976.

[37] G.P. Smith, D.M. Golden, M. Frenklach, N.W. Moriarty, B. Eiteneer, M. Goldenberg, C.T.

Bowman, R.K. Hanson, S. Song, W.C. Gardiner Jr., V.V. Lissianski, Z. Qin, in, http://www.me.berkeley.edu/gri_mech/ 2015.

[38] K.J. Hughes, T. Turányi, A.R. Clague, M.J. Pilling, Int. J. Chem. Kinet., 33 (2001) 513-538. [39] H. Wang, X. You, A.V. Joshi, S.G. Davis, A. Laskin, F. Egolfopoulos, C.K. Law, USC Mech Version II. High-Temperature Combustion Reaction Model of H2/CO/C1-C4 Compounds, http://ignis.usc.edu/USC Mech_II.htm, 2007.

[40] G. Bourque, D. Healy, H. Curran, C. Zinner, D. Kalitan, J. de Vries, C. Aul, E. Petersen, Proceedings of the Asme Turbo Expo 2008, Vol 3, Pts a and B, 3 (2008) 1051-1066. 
[41] X. Zhou, C. Chen, F. Wang, Int. J. Hydrogen Energy, 35 (2010) 1620-1629.

[42] M. Vascellari, H. Xu, S. Hartl, F. Hunger, C. Hasse, Chem. Eng. Sci., 134 (2015) 694-707.

[43] W. Guo, Y. Wu, L. Dong, C.X. Chen, F.C. Wang, Fuel Process. Technol., 98 (2012) 45-50.

[44] Y. Liu, T. Wang, Q. Li, D. Wang, Chin. J. Chem. Eng., 19 (2011) 424-433.

[45] P. Oßwald, M. Köhler, Rev. Sci. Instrum., 86 (2015) 044510.

[46] N. Hansen, T.A. Cool, P.R. Westmoreland, K. Kohse-Höinghaus, Progr. Energy Combust. Sci., 35 (2009) 168-191.

[47] F. Qi, Proc. Combust. Inst., 34 (2013) 33-63.

[48] S.M. Sarathy, P. Oßwald, N. Hansen, K. Kohse-Höinghaus, Progr. Energy Combust. Sci., 44 (2014) 40-102.

[49] B. Yang, C.K. Westbrook, T.A. Cool, N. Hansen, K. Kohse-Höinghaus, Proc. Combust. Inst., 34 (2013) 443-451.

[50] D. Liu, C. Togbé, L.-S. Tran, D. Felsmann, P. Oßwald, P. Nau, J. Koppmann, A. Lackner, P.A. Glaude, B. Sirjean, R. Fournet, F. Battin-Leclerc, K. Kohse-Höinghaus, Combust. Flame, 161 (2014) 748-765.

[51] A. Lucassen, P. Oßwald, U. Struckmeier, K. Kohse-Höinghaus, T. Kasper, N. Hansen, T.A. Cool, P.R. Westmoreland, Proc. Combust. Inst., 32 (2009) 1269-1276.

[52] C. Togbé, L.-S. Tran, D. Liu, D. Felsmann, P. Oßwald, P.A. Glaude, B. Sirjean, R. Fournet, F. Battin-Leclerc, K. Kohse-Höinghaus, Combust. Flame, 161 (2014) 780-797.

[53] L.-S. Tran, C. Togbé, D. Liu, D. Felsmann, P. Oßwald, P.A. Glaude, R. Fournet, B. Sirjean, F. Battin-Leclerc, K. Kohse-Höinghaus, Combust. Flame, 161 (2014) 766-779.

[54] F. Herrmann, P. Oßwald, K. Kohse-Höinghaus, Proc. Combust. Inst., 34 (2013) 771-778.

[55] T. Kasper, P. Oßwald, U. Struckmeier, K. Kohse-Höinghaus, C.A. Taatjes, J. Wang, T.A. Cool, M.E. Law, A. Morel, P.R. Westmoreland, Combust. Flame, 156 (2009) 1181-1201.

[56] E. Bartholome, Chem. Eng. Sci., 3, Supplement 1 (1954) 94-104.

[57] J.C. Biordi, Progr. Energy Combust. Sci., 3 (1977) 151-173.

[58] P. Oßwald, H. Güldenberg, K. Kohse-Höinghaus, B. Yang, T. Yuan, F. Qi, Combust. Flame, 158 (2011) 2-15.

[59] P. Oßwald, P. Hemberger, T. Bierkandt, E. Akyildiz, M. Köhler, A. Bodi, T. Gerber, T. Kasper, Rev. Sci. Instrum., 85 (2014) 025101.

[60] P. Oßwald, K. Kohse-Höinghaus, U. Struckmeier, T. Zeuch, L. Seidel, L. Leon, F. Mauss, Z. Phys. Chem., 225 (2011) 1029-1054.

[61] M. Schenk, L. Leon, K. Moshammer, P. Oßwald, T. Zeuch, L. Seidel, F. Mauss, K. KohseHöinghaus, Combust. Flame, 160 (2013) 487-503.

[62] F. Herrmann, B. Jochim, P. Oßwald, L. Cai, H. Pitsch, K. Kohse-Höinghaus, Combust. Flame, 161 (2014) 384-397.

[63] Chemical WorkBench® 4.0, Kintech laboratory, http://www.kintechlab.com/products/chemicalworkbench/, (2013).

[64] V. Chernov, M.J. Thomson, S.B. Dworkin, N.A. Slavinskaya, U. Riedel, Combust. Flame, 161 (2014) 592-601.

[65] F. Battin-Leclerc, Progr. Energy Combust. Sci., 34 (2008) 440-498.

[66] E. Ranzi, A. Sogaro, P. Gaffuri, G. Pennati, T. Faravelli, Combust. Sci. Technol., 96 (1994) 279325.

[67] J. Wang, M. Chaos, B. Yang, T.A. Cool, F.L. Dryer, T. Kasper, N. Hansen, K. Kohse-Höinghaus, P.R. Westmoreland, Phys. Chem. Chem. Phys., 11 (2009) 1328-1339.

[68] N. Hansen, T. Kasper, B. Yang, T.A. Cool, W. Li, P.R. Westmoreland, P. Oßwald, K. KohseHöinghaus, Proc. Combust. Inst., 33 (2011) 585-592. 


\section{Figures}

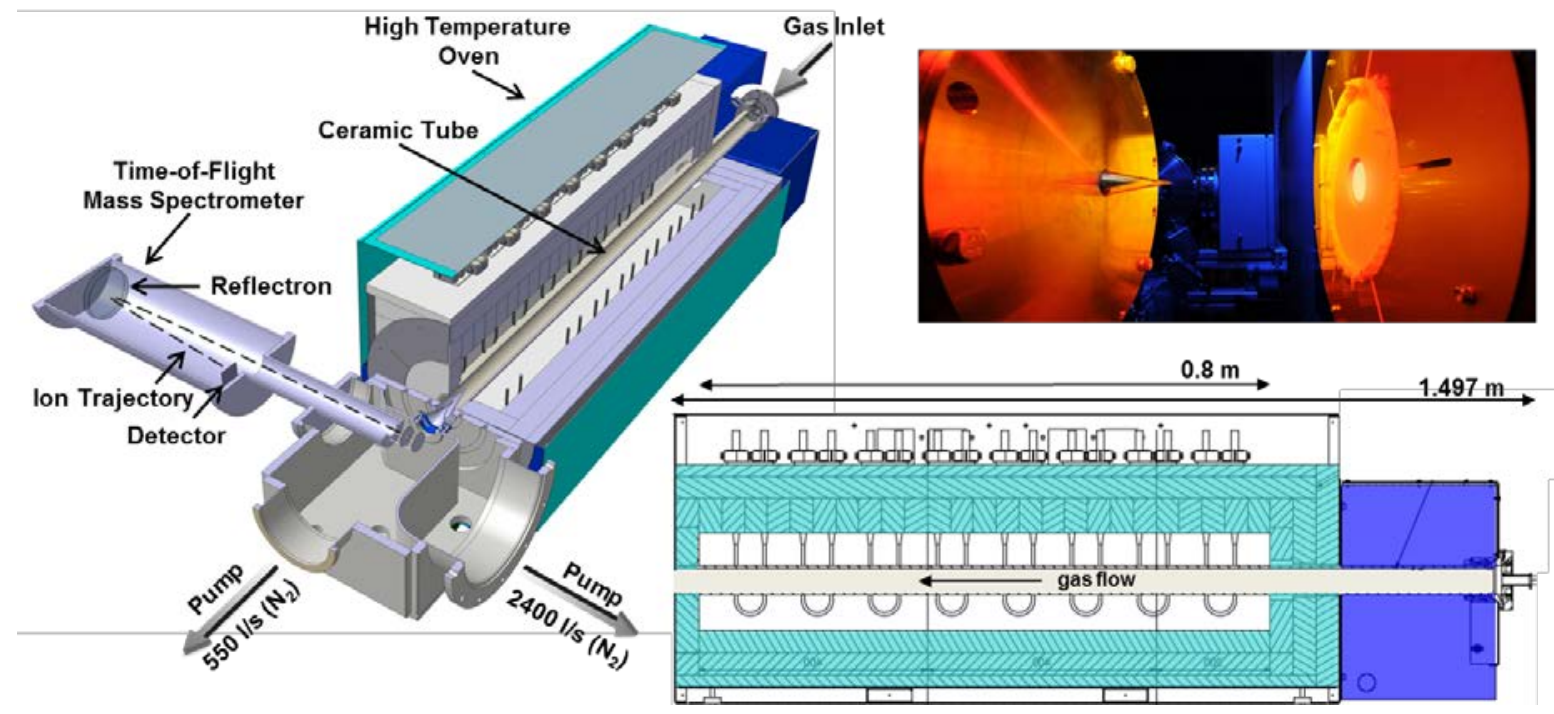

Fig. 1: Schematic DLR high-temperature flow reactor and photograph, details in [45]. 

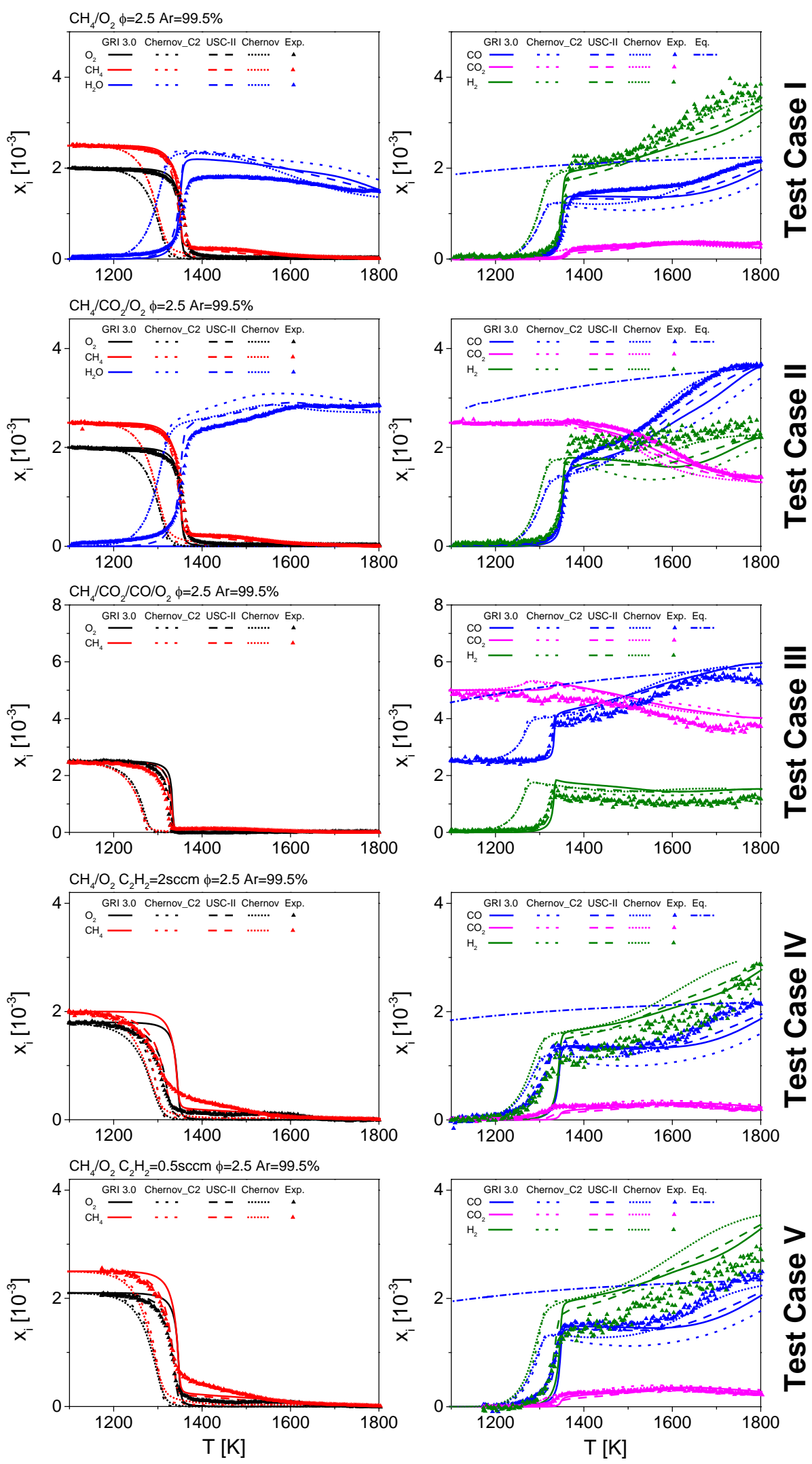

Fig. 2: Measured (symbols) and computed (lines) major species mole fraction profiles as a function of the respective oven temperatures (T) for the 5 methane based test cases. Fuel and $\mathrm{O}_{2}$ left side; $\mathrm{H}_{2}$, $\mathrm{CO}$ and $\mathrm{CO}_{2}$ right side. Chemical equilibrium is additionally shown for $\mathrm{CO}$. 

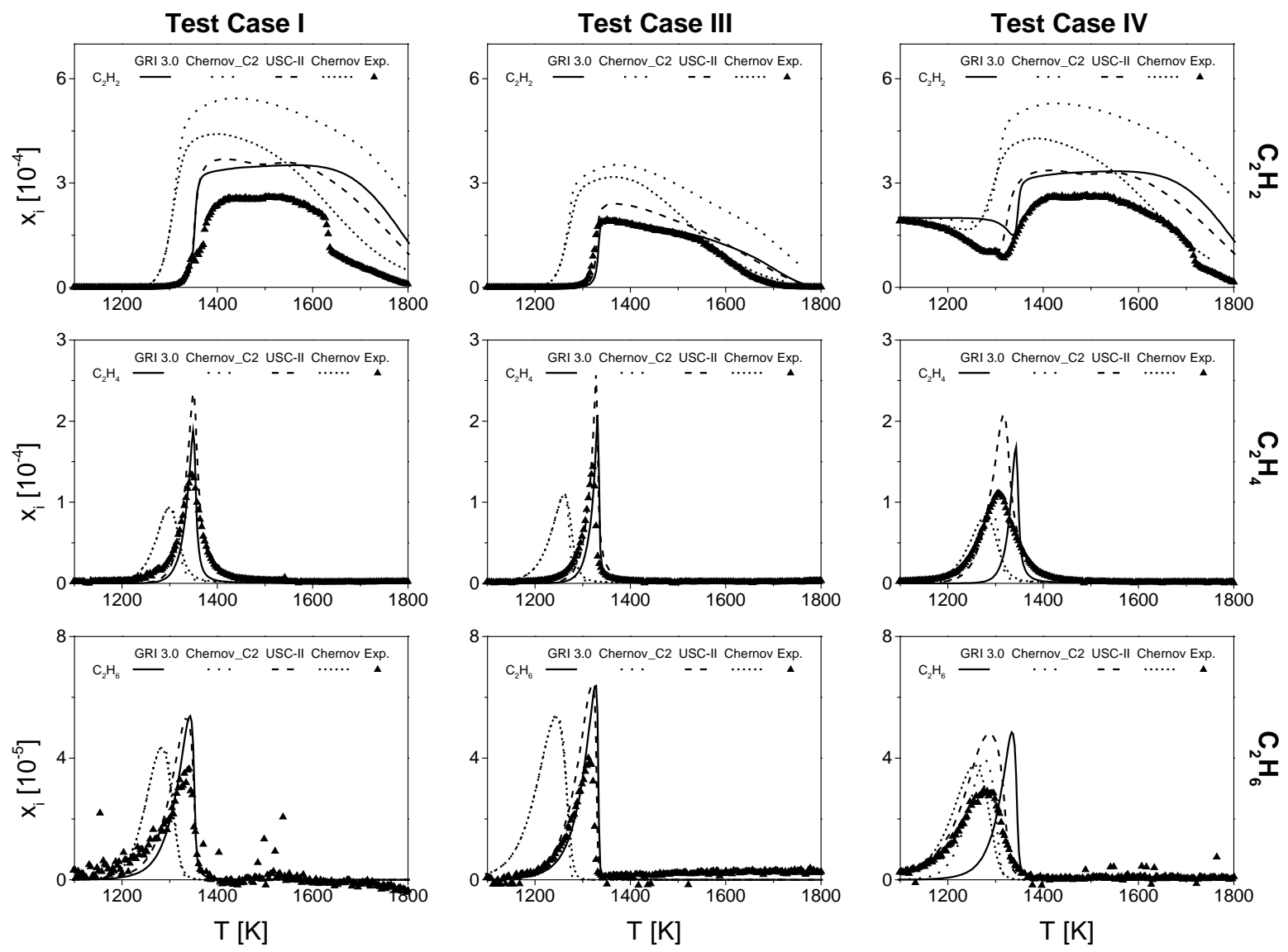

Fig. 3: Mole fraction profiles of the $\mathrm{C}_{2} \mathrm{H}_{2}, \mathrm{C}_{2} \mathrm{H}_{4}$ and $\mathrm{C}_{2} \mathrm{H}_{6}$ intermediates as a function of the respective oven temperatures (T) for selected test cases I, III and IV. Symbols represent experimental data and lines represent modeling results. No scaling factor is applied.
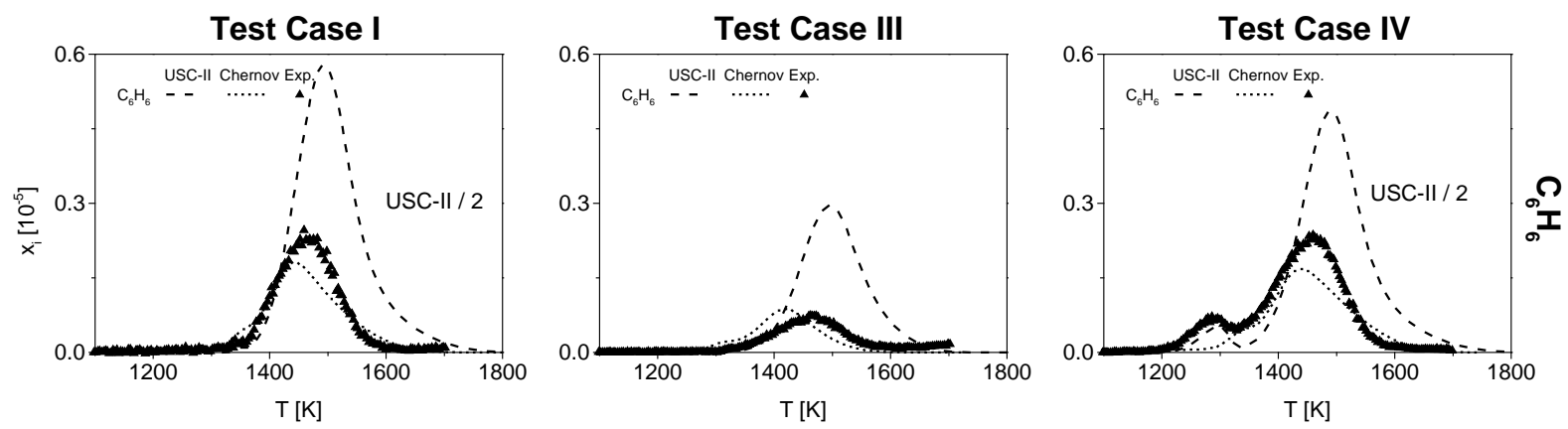

Fig. 4: Mole fraction profiles of the $\mathrm{C}_{6} \mathrm{H}_{6}$ as a function of the respective oven temperatures (T) for selected test cases I, III and IV. Symbols represent experimental data and lines represent modeling results. Note, that GRI 3.0 and Chernov_C2 mechanism do not include benzene. No scaling factor is applied. 

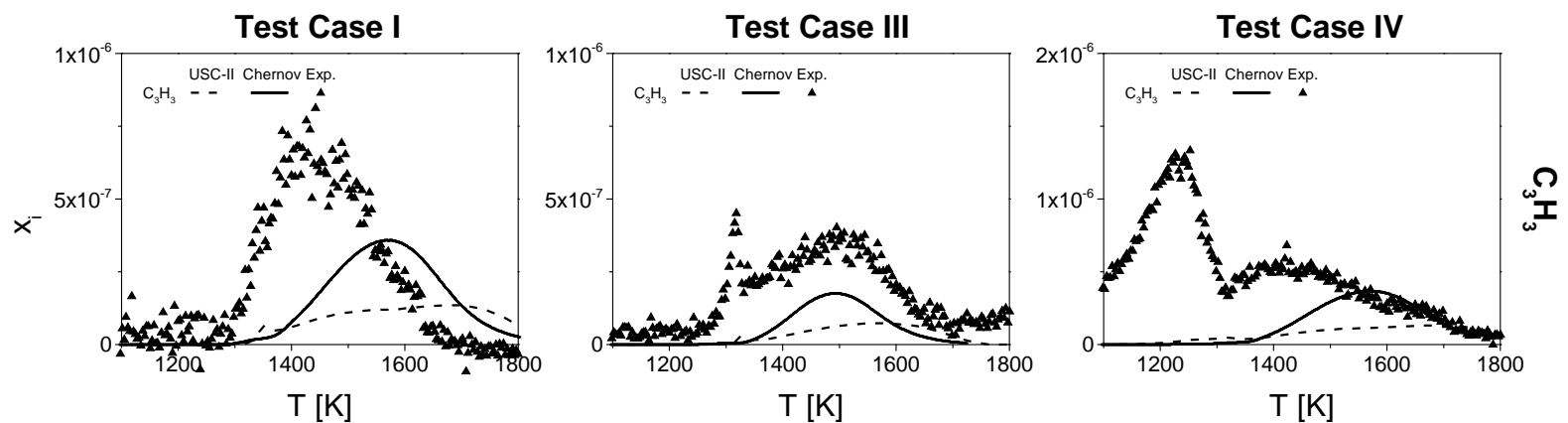

Fig. 5: Mole fraction profiles of the $\mathrm{C}_{3} \mathrm{H}_{3}$ as a function of the respective oven temperatures (T) for selected test cases I, III and IV. Symbols represent experimental data and lines represent modeling results. No scaling factor is applied.
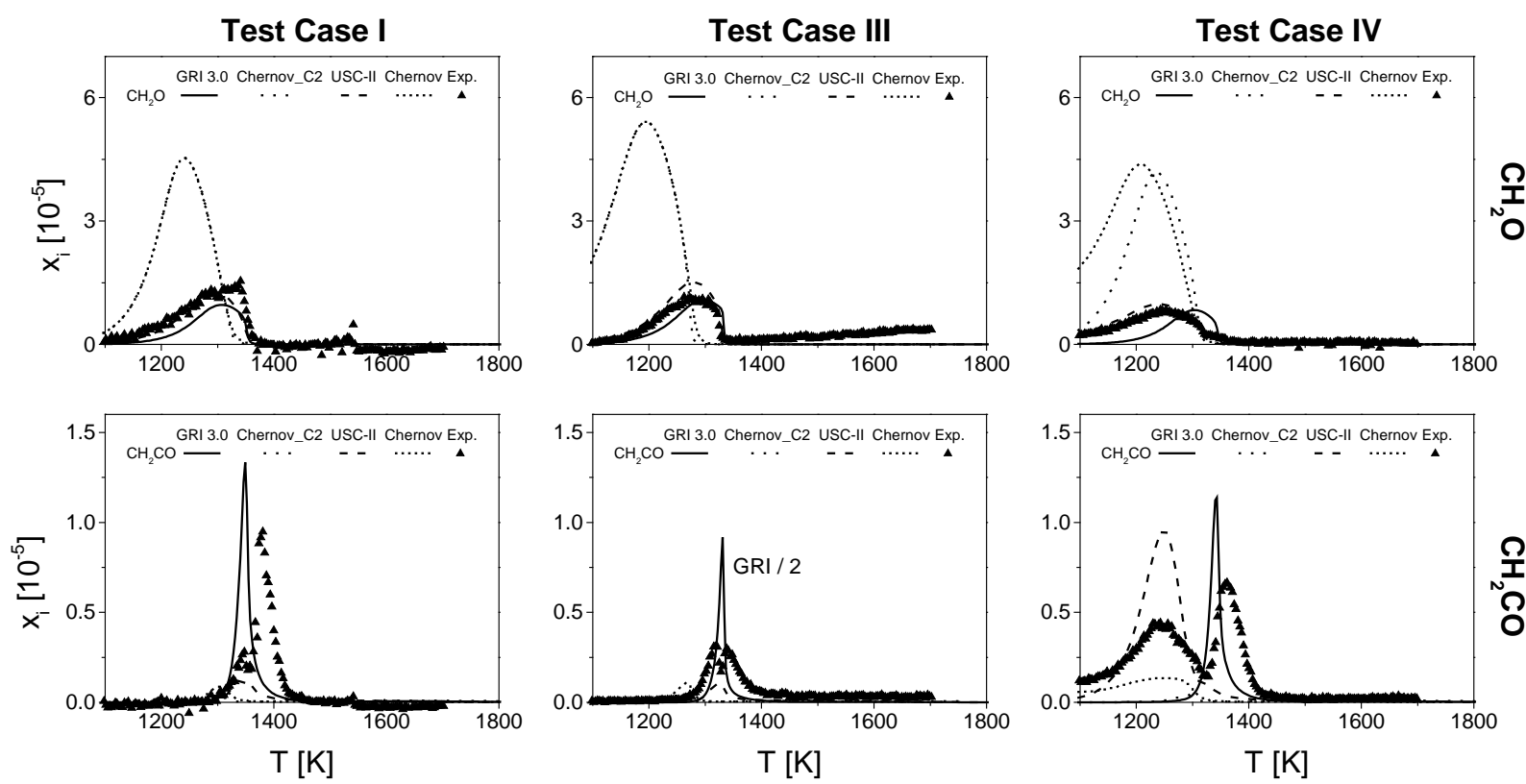

Fig. 6: Mole fraction profiles of the $\mathrm{CH}_{2} \mathrm{O}$ and $\mathrm{CH}_{2} \mathrm{CO}$ as a function of the respective oven temperatures (T) for selected test cases I, III and IV. Symbols represent experimental data and lines represent modeling results. No scaling factor is applied. 